\title{
Safety and efficacy of video-assisted versus conventional lung resection for lung cancer
}

\author{
Farhood Farjah, MD, MPH, ${ }^{a}$ Douglas E. Wood, MD, ${ }^{b}$ Michael S. Mulligan, MD, ${ }^{b}$ Bahirathan Krishnadasan, MD, \\ Patrick J. Heagerty, PhD, ${ }^{\mathrm{c}}$ Rebecca Gaston Symons, MPH, ${ }^{\mathrm{a}}$ and David R. Flum, MD, MPH ${ }^{\mathrm{a}, \mathrm{d}}$
}

Objective: We sought to evaluate the use of video-assisted thoracoscopy among patients with lung cancer and its safety and effectiveness relative to conventional resection.

\begin{abstract}
Methods: A cohort study (1994-2002) was conducted by using the Surveillance, Epidemiology, and End-Results Medicare database. Video-assisted thoracoscopy and conventional resection were hypothesized to be equivalent in terms of risks of death. Equivalency was defined by a confidence interval of 0.72 to 1.28 for the odds of 30-day death and 0.89 to 1.11 for the hazard of death, corresponding to a difference of no more than $1 \%$ for 30 -day mortality and $5 \%$ for 5 -year survival, respectively.

Results: Among 12,958 patients who underwent segmentectomy or lobectomy (mean age, $74 \pm 5$ years), $6 \%$ underwent video-assisted thoracoscopy. The use of video-assisted thoracoscopy increased from $1 \%$ to $9 \%$ between 1994 and 2002. Compared with those who underwent conventional resection, patients who underwent video-assisted thoracoscopy more frequently had smaller tumors $(P<.001)$ and stage I disease $(P=.03)$, underwent lymphadenectomy $(P<.001)$, and were cared for by higher-volume surgeons $(P<.001)$ and at highervolume hospitals $(P<.001)$. After adjusting for differences in patient, cancer, management, and provider characteristics, the odds of early death were not significantly different between patients undergoing video-assisted thoracoscopy and those undergoing conventional resection, although equivalency was not demonstrated (adjusted odds ratio, $0.93 ; 95 \%$ confidence interval, $0.57-1.50$ ). The hazard of death was equivalent for video-assisted thoracoscopy and conventional resection (adjusted hazard ratio, 0.99; 95\% confidence interval, 0.90-1.08).
\end{abstract}

Conclusions: Video-assisted thoracoscopy was uncommonly used to manage lung cancer, although its use has increased over time. Video-assisted thoracoscopy and conventional resection were equivalent in terms of longterm survival.

Although an increasing body of evidence supports the use of video-assisted thoracoscopy (VATS) in lung cancer management, ${ }^{1-16}$ it is unclear how widely it is being used. Additionally, it is unknown whether the safety and effectiveness of this relatively new procedure is equivalent to that of open thoracotomy.

New technology and therapeutic interventions can offer advantages over standard treatment without compromising well-established safety and efficacy benchmarks, but determining whether 2 competing therapies are equivalent is methodologically challenging. Standard hypothesis testing cannot prove equivalence, even when the outcomes of 2 treatments are not significantly different. A well-accepted

\footnotetext{
From the Surgical Outcomes Research Center, Department of Surgery ${ }^{\mathrm{a}}$ and the Division of Cardiothoracic Surgery, ${ }^{\mathrm{b}}$ Department of Surgery, the Department of Biostatistics, ${ }^{\mathrm{c}}$ and the Division of General Surgery, Department of Surgery, ${ }^{\mathrm{d}}$ University of Washington, Seattle, Wash.

Dr Farjah was supported by a Cancer Epidemiology and Biostatistics Training Grant (T32 CA09168-30) and Ruth L. Kirschstein National Research Service Award (F32 CA130434-01) from the National Cancer Institute.

Received for publication May 19, 2008; revisions received Sept 28, 2008; accepted for publication Nov 22, 2008.

Address for reprints: David R. Flum, MD, MPH, Department of Surgery, University of Washington, 1959 NE Pacific, Box 356410, Seattle, WA 98195-6310 (E-mail: daveflum@u.washington.edu).

J Thorac Cardiovasc Surg 2009;137:1415-21

$0022-5223 / \$ 36.00$

Copyright (c) 2009 by The American Association for Thoracic Surgery

doi:10.1016/j.jtcvs.2008.11.035
}

method of evaluating equivalency is a noninferiority randomized trial: a study designed to rule out the possibility of prespecified, clinically important differences in outcomes between treatment groups. ${ }^{17}$ Because the feasibility of a randomized trial of VATS versus conventional resection has been questioned, a noninferiority-based analysis of observational data might be informative.

Using a nationally representative tumor registry linked to Medicare claims and a noninferiority-based analytic framework, we described the use and associated outcomes of VATS among patients with lung cancer who underwent segmentectomy or lobectomy. We hypothesized that the safety (30-day case fatality) and effectiveness (long-term survival) of VATS and conventional resection would be equivalent. Clinically important differences of $1 \%$ for 30 -day case fatality and 5\% for 5-year survival were specified a priori.

\section{MATERIALS AND METHODS}

The Surveillance, Epidemiology, and End-Results (SEER) Medicare database was used to perform a retrospective cohort study of patients given diagnoses of lung cancer from 1994 through 2002. SEER captures approximately $14 \%$ of incident malignancies in the United States. Tumor registry data have been linked to claims data among SEER patients who were Medicare beneficiaries. The utility, quality, and validity of the SEER-Medicare database have been described previously. ${ }^{18}$ The University of Washington Institutional Review Board approved this study and waived consent.

Among 191,024 patients given diagnoses of lung cancer from 1994 through 2002, the following sequential exclusions were made: patients 


\author{
Abbreviations and Acronyms \\ CI = confidence interval \\ HCPCS $=$ Healthcare Common Procedure \\ Coding System \\ LOS = length of stay \\ SEER = Surveillance, Epidemiology, \\ and End-Results \\ VATS $=$ video-assisted thoracoscopy
}

given diagnoses at autopsy/death $(\mathrm{n}=4379)$, patients who did not undergo segmentectomy or lobectomy $(n=170,258)$, patients less than 66 years old $(n=1370)$, diagnosis of a second malignancy between 3 months before and 6 months after lung cancer diagnosis $(\mathrm{n}=812)$, and patients with only part A or part B, concurrent health maintenance organization enrollment, or both between 1 year before and 6 months after lung cancer diagnosis $(n=1247)$. These exclusions were made to ensure the accuracy and completeness of claims data when used for the purposes of research, and the specific reasons for the exclusions have been described previously. ${ }^{19}$

Outcomes included long-term survival, death within 30 days of the operation, length of stay (LOS), and Medicare expenditures. Death data were available through the Medicare Enrollment Database with follow-up through 2005. LOS and Medicare expenditure information were available from the Medicare Provider Analysis and Review file. Costs were defined by the actual dollar amount paid by Medicare to the hospital (expenditures) rather than hospital charges and adjusted for inflation by using the Consumer Price Index for Medical Care.

Patient and disease characteristics were available through the SEER registry, and management and provider information was available through Medicare claims. Indicators of low income or education were based on the lowest quartiles of median income and proportion with a high-school education within a given zip code. Geography was defined by the SEER registry where the patient was diagnosed. Residence refers to the population size of the area where the patient lived. Claims within the carrier and outpatient files in the year before diagnosis were used to ascertain the Klabundemodified Charlson Comorbidity Index. ${ }^{20}$ Tumor size, stage (American Joint Committee on Cancer, sixth edition), and histology were based on all available information within 4 months of diagnosis. The use of mediastinal staging modalities was ascertained by using claims defined by the Healthcare Common Procedure Coding System (HCPCS) and present within the carrier claims files, outpatient files, or both. Resection type, radiation therapy, and chemotherapy were defined by using the carrier claim files with relevant HCPCS; by using the outpatient files with relevant HCPCS codes, International Classification of Diseases (Ninth Revision) procedure codes, and Revenue Center Codes (Appendix 1); or both. Hospital teaching status was determined by linkage to Medicare hospital files. Volume measurements reflected average yearly provider volume among SEER-Medicare patients but not total provider volume. ${ }^{21} \mathrm{~A}$ dichotomous variable was created to indicate higher-volume providers based on those within the highest quartile of volume.

STATA (Special Edition 9.2; StataCorp, College Station, Tex) was used for all statistical analyses. Continuous and categorical variables were compared by using a $t$ test for independent samples and the $\chi^{2}$ test, respectively. The Kaplan-Meier method was used to obtain unadjusted survival estimates. A priori designated potential confounders included patient (age, sex, race, and comorbidity index), cancer (stage, histology, and tumor size), management (mediastinoscopy, mediastinal lymphadenectomy, and neoadjuvant therapy), and provider (surgeon volume and hospital volume and teaching status) characteristics. The analytic strategy was to sequentially add groups of variables to regression models to better understand how these variables might confound unadjusted comparisons. Cox propor- tional-hazards models were used to evaluate the relationship between approach to resection and overall survival while providing adjustment for potential confounders. Survival time was defined as the interval between the date of diagnosis and the date of death or censoring. The proportional-hazards assumption was tested by using Schoenfeld residuals. In the event the assumption was not satisfied, extended (stratified) Cox regression models were used. Logistic regression models were used to examine the relationship between approach to resection and 30-day mortality while providing adjustment for potential confounders. Linear regression was used to evaluate the relationship between approach to resection and LOS and expenditures while providing adjustment for potential confounders. Because the distributions of LOS and expenditures were not normal, both variables were $\log$ transformed, and geometric means were reported. All multivariable regression models adjusted for clustering at the hospital level.

Confidence interval (CI) inspection was used to conduct a noninferiority-based analysis. Because regression models estimate relative risk, prespecified noninferiority risk differences were expressed in terms of relative risk by using the conventional resection group's outcomes as baseline. CIs defining equivalence were 0.72 to 1.28 for the odds of early death and 0.89 to 1.11 for the hazard of death, corresponding to a difference of no greater than $1 \%$ for 30 -day mortality and $5 \%$ for 5 -year survival, respectively. Derived CIs falling within these ranges indicated equivalence. If the upper bounds of the derived CIs exceeded the upper bounds of the predetermined equivalency intervals, then inferiority could not be excluded. Similarly, if the lower bounds of derived CIs exceeded the lower bounds of prespecified equivalency intervals, then superiority could not be excluded.

\section{RESULTS}

Between 1994 and 2002, 12,958 patients with lung cancer underwent segmentectomy or lobectomy performed by 1600 surgeons at 781 hospitals. Six percent of patients underwent VATS resection by $7 \%$ of surgeons and at $13 \%$ of hospitals. The frequency of VATS use increased over time among patients, surgeons, and hospitals (Figure 1).

Patients who underwent VATS or open resection were dissimilar in many ways (Table 1). Compared with patients who underwent conventional resection, those who underwent VATS were older (76 vs 74 years, $P<.001$ ); more commonly lived in the West $(61 \%$ vs $42 \%, P<.001)$ or

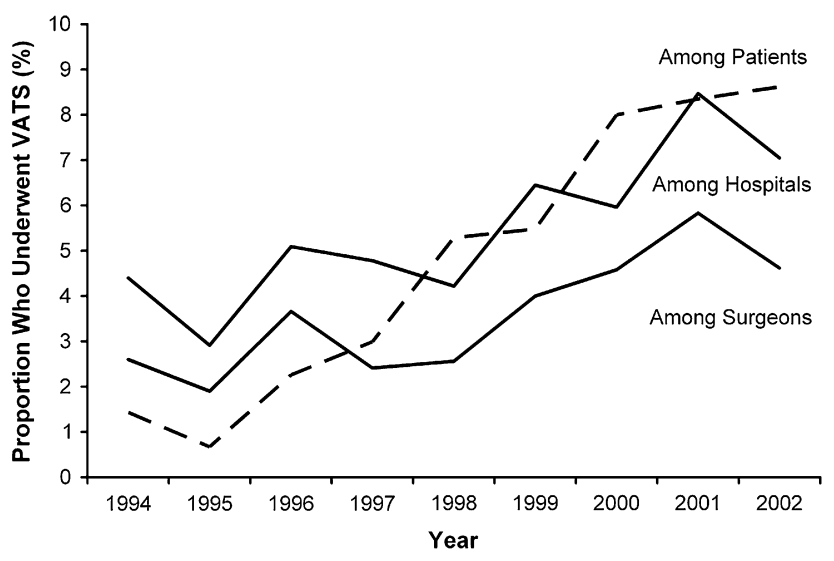

FIGURE 1. Temporal trends in the use of video-assisted thoracoscopy (VATS) among patients, surgeons, and hospitals. 
TABLE 1. Patient and disease characteristics by approach to resection

\begin{tabular}{|c|c|c|c|c|}
\hline & $\begin{array}{c}\text { All } \\
(\mathrm{n}=12,958)(\mathrm{r}\end{array}$ & $\begin{array}{c}\text { Open } \\
=12,237)\end{array}$ & $\begin{array}{c}\text { Thoracoscopic } \\
(\mathbf{n}=\mathbf{7 2 1})\end{array}$ & $\begin{array}{c}P \\
\text { value* }^{*}\end{array}$ \\
\hline Age, y $(\%)$ & & & & $<.001$ \\
\hline $66-70$ & 27 & 27 & 21 & \\
\hline $71-75$ & 34 & 34 & 32 & \\
\hline $76-80$ & 26 & 26 & 28 & \\
\hline $81-85$ & 11 & 11 & 16 & \\
\hline$\geq 86+$ & 2 & 2 & 5 & \\
\hline Mean \pm SD & $74 \pm 5$ & $74 \pm 5$ & $76 \pm 6$ & $<.001$ \\
\hline Male sex $(\%)$ & 51 & 51 & 45 & .01 \\
\hline Race $(\%)$ & & & & .10 \\
\hline White & 89 & 89 & 92 & \\
\hline Black & 5 & 5 & 4 & \\
\hline Other & 5 & 5 & 5 & \\
\hline Missing & $<1$ & $<1$ & $<1$ & \\
\hline Income $(\%)$ & & & & $<.001$ \\
\hline Lowest quartile & 24 & 24 & 14 & \\
\hline Missing & 4 & 4 & 3 & \\
\hline Education $(\%)$ & & & & $<.001$ \\
\hline Lowest quartile & 24 & 24 & 18 & \\
\hline Missing & 4 & 4 & 3 & \\
\hline Marital status (\%) & & & & $<.001$ \\
\hline Unmarried & 38 & 38 & 41 & \\
\hline Missing & 4 & 4 & 1 & \\
\hline Geography (\%) & & & & $<.001$ \\
\hline West & 43 & 43 & 61 & \\
\hline East & 21 & 21 & 33 & \\
\hline Midwest & 23 & 23 & 4 & \\
\hline South & 13 & 13 & 2 & \\
\hline Residence (\%) & & & & $<.001$ \\
\hline Metropolitan & 87 & 87 & 96 & \\
\hline Urban & 6 & 6 & 2 & \\
\hline Rural & 8 & 8 & 2 & \\
\hline Prior malignancy $(\%)$ & 23 & 23 & 29 & $<.001$ \\
\hline Comorbidity index $(\%)$ & & & & .40 \\
\hline 0 & 54 & 54 & 52 & \\
\hline 1 & 30 & 30 & 30 & \\
\hline 2 & 11 & 11 & 11 & \\
\hline$\geq 3$ & 6 & 6 & 7 & \\
\hline Histology (\%) & & & & $<.001$ \\
\hline NSCLC & & & & \\
\hline Adenocarcinoma & 56 & 56 & 64 & \\
\hline Squamous & 29 & 29 & 23 & \\
\hline Large cell & 5 & 5 & 3 & \\
\hline Undifferentiated & 2 & 2 & 2 & \\
\hline NOS & 3 & 3 & 2 & \\
\hline SCLC & 1 & 2 & 1 & \\
\hline Other & 4 & 4 & 5 & \\
\hline Stage $(\%)$ & & & & .01 \\
\hline I & 61 & 61 & 65 & \\
\hline II & 12 & 12 & 9 & \\
\hline IIIA & 7 & 7 & 5 & \\
\hline IIIB & 4 & 4 & 6 & \\
\hline IV & 3 & 3 & 4 & \\
\hline Missing & 13 & 13 & 11 & \\
\hline
\end{tabular}

TABLE 1. Continued

\begin{tabular}{lcccc}
\hline & All & Open & Thoracoscopic & $P$ \\
& $(\mathbf{n}=\mathbf{1 2 , 9 5 8})(\mathbf{n}=\mathbf{1 2 , 2 3 7})$ & $(\mathbf{n}=\mathbf{7 2 1})$ & value* $^{*}$ \\
\hline Size & & & & \\
Mean \pm SD, cm & $3.3 \pm 2.0$ & $3.3 \pm 2.0$ & $2.8 \pm 1.6$ & $<.001$ \\
$>3$ cm (\%) & 40 & 41 & 29 & $<.001$ \\
Missing (\%) & 5 & 5 & 3 & \\
Location (\%) & & & & .16 \\
RUL & 31 & 31 & 31 & \\
RML & 5 & 5 & 5 & \\
RLL & 18 & 18 & 18 & \\
LUL & 28 & 29 & 28 & \\
LLL & 15 & 16 & 15 & \\
Missing & 3 & 3 & 3 & \\
\hline
\end{tabular}

$S D$, Standard deviation; $N S C L C$, non-small cell lung cancer; $N O S$, histology not otherwise specified; $S C L C$, small cell lung cancer; $R U L$, right upper lobe; $R M L$, right middle lobe; $R L L$, right lower lobe; $L U L$, left upper lobe; $L L L$, left lower lobe. $* P$ value for tests comparing thoracoscopic and open resection.

metropolitan areas $(96 \%$ vs $86 \%, P<.001)$; more commonly had a prior malignancy $(29 \%$ vs $22 \%, P<.001)$, stage I disease ( $65 \%$ vs $61 \%, P=.03)$, or adenocarcinoma $(64 \%$ vs $55 \%, P<.001)$; and were less frequently in lowincome $(14 \%$ vs $25 \%, P<.001)$ or low-education $(18 \%$ vs $24 \%, P<.001)$ strata. The mean tumor size was significantly smaller among patients who underwent VATS $(2.8$ vs $3.4 \mathrm{~cm}, P<.001$ ). No significant differences in the distribution of race or comorbidity index were observed.

Perioperative management varied by approach to resection (Table 2). Compared with those in the conventional resection group, patients in the VATS group more often underwent mediastinal lymphadenectomy ( $45 \%$ vs $26 \%, P<$ $.001)$ and neoadjuvant therapy ( $8 \%$ vs $6 \%, P<.001)$. During the period when claims for positron emission tomography were available (1998-2002), patients undergoing VATS more often underwent positron emission tomography $(51 \%$ vs $29 \%, P<.001)$. Those in the VATS group less frequently received adjuvant therapy $(15 \%$ vs $20 \%$, $P<.001)$. There was no significant difference in the use of mediastinoscopy between groups.

Provider characteristics also varied by approach to resection (Table 2). Compared with those who underwent conventional resection, patients who underwent VATS were cared for by a higher proportion of higher-volume surgeons $(92 \%$ vs $75 \%, P<.001)$ and more frequently at higher-volume $(88 \%$ vs $75 \%, \mathrm{p}<0.001)$ and teaching $(84 \%$ vs $63 \%$, $P<.001)$ hospitals.

In the unadjusted analysis VATS was associated with significantly higher 5-year overall survival rates compared with those after conventional resection ( $48 \%$ vs $44 \%, P=.02)$, although 30-day mortality rates were not significantly different $(3.2 \%$ vs $3.6 \%, P=.53)$. VATS was associated with shorter LOS (4 vs 8 days, $P<.001)$ but higher Medicare expenditures $(\$ 20,519$ vs $\$ 19,786, P=.008)$. 
TABLE 2. Management and provider characteristics by approach to resection

\begin{tabular}{|c|c|c|c|c|}
\hline & All $(n=12,958)$ & Open $(n=12,237)$ & Thoracoscopic $(\mathrm{n}=\mathbf{7 2 1})$ & $P$ value* \\
\hline \multicolumn{5}{|l|}{ Staging $(\%)$} \\
\hline $\mathrm{PET} \dagger$ & 30 & 30 & 51 & $<.001$ \\
\hline Mediastinoscopy & 16 & 16 & 17 & .49 \\
\hline Neoadjuvant therapy $(\%)$ & 6 & 6 & 8 & $<.001$ \\
\hline Mediastinal lymphadenectomy (\%) & 27 & 26 & 45 & $<.001$ \\
\hline Adjuvant therapy (\%) & 20 & 20 & 15 & $<.001$ \\
\hline Higher-volume surgeon (\%) & 76 & 75 & 92 & $<.001$ \\
\hline Missing & 1 & 1 & 1 & \\
\hline Higher-volume hospital (\%) & 76 & 75 & 88 & $<.001$ \\
\hline Missing & 2 & 2 & 2 & \\
\hline Teaching institution (\%) & 64 & 63 & 84 & $<.001$ \\
\hline Missing & 2 & 2 & 2 & \\
\hline
\end{tabular}

After adjustment, the odds of 30-day death were not significantly different when comparing VATS with open resection, although equivalency was not established based on noninferiority criteria (Table 3 ). In models evaluating survival, the hazards of death for VATS and open resection were equivalent in the fully adjusted model. In an exploratory analysis VATS and open resection were also equivalent in terms of the hazards of lung cancer cause-specific death (adjusted hazard ratio, 0.99; 95\% CI, 0.88-1.11; noninferiority bounds, $0.86-1.14)$. VATS was associated with a significantly shorter LOS compared with conventional resection (adjusted risk difference, -5 days; $95 \% \mathrm{CI},-7$ to -2 days), although Medicare expenditures were not significantly different (adjusted risk difference, \$290; 95\% CI, $-\$ 1603$ to $\$ 2182$ ). Adjustment for all measured variables (eg, income and education) had no substantial bearing on any of the findings from the primary analyses. Sensitivity analyses with 3 different methods of propensity scoring (ie, adjustment matching, stratification, and regression) yielded results that were largely similar to those of our primary analysis.

Finally, a stratified analysis was conducted to explore whether VATS and conventional resection were equivalent in terms of survival when performed by different provider types (Table 4). VATS was at least as effective as conventional resection when performed by higher-volume surgeons or at higher-volume and teaching hospitals. When performed by lower-volume surgeons or at lower-volume or nonteaching hospitals, point estimates suggested higher hazards of death associated with VATS, although this apparent association was not statistically significant.

\section{DISCUSSION}

The goals of this investigation were to describe the use and associated outcomes of VATS resection for lung cancer and evaluate whether this minimally invasive approach to pulmonary resection was as safe and effective as the standard. VATS was infrequently used for cancer management, although its use increased over time. The risks of early death after VATS were not significantly different from those after conventional resection, although equivalency could not be confirmed. After adjustment, VATS was as effective as conventional resection in terms of long-term survival. VATS might have been inferior to open resection when performed by lower-volume surgeons and hospitals.

Several reasons might explain the infrequent use of VATS for lung cancer management. Surgeons might be uncomfortable performing VATS because of insufficient training or experience with this minimally invasive procedure. Some surgeons might believe that there is an insufficient level of evidence to confirm the safety and efficacy of VATS compared with standard resection and might be skeptical about its purported benefits. In the setting of malignancy in particular, surgeons might demand higher levels of evidence than they might for benign conditions. This notion might explain the relatively slow adoption of a laparoscopic approach to colon cancer resection, ${ }^{22}$ despite rapid adoption of laparoscopy for conditions such as symptomatic cholelithiasis, obesity, and gastroesophageal reflux. ${ }^{23-25}$ The lack of operating room resources or staff might also be a barrier to the use of VATS.

Several lines of evidence support the notion that VATS is at least as safe as conventional resection. By avoiding rib spreading, muscle splitting, and the use of a retractor, VATS is believed to result in less pain, earlier ambulation, fewer postoperative complications, and possibly fewer early deaths. Consistent with this claim, several reports show lower rates of postoperative complications associated with VATS when compared with conventional resection. ${ }^{1,6,16}$ Equivalent risks of early death were not demonstrated in this study for several possible reasons. First, most investigations, including this one, were probably underpowered to exclude the possibility of small prespecified differences in rare events, such as death. ${ }^{26}$ Alternatively, large variability in risks of early death might reflect actual variability in outcomes rather than statistical noise. If true, this explanation 
TABLE 3. Multivariable analysis of safety and effectiveness of VATS relative to conventional resection

\begin{tabular}{|c|c|c|}
\hline & HR $_{\text {survival }}(95 \% \mathrm{CI})$ & $\begin{array}{c}\text { Equivalence } \\
\text { interval } \\
\end{array}$ \\
\hline \multicolumn{3}{|l|}{ VATS vs conventional } \\
\hline Unadjusted & $0.89(0.79-0.99)$ & \\
\hline $\begin{array}{l}\text { Add patient } \\
\text { characteristics }\end{array}$ & $0.85(0.76-0.95)$ & \\
\hline $\begin{array}{l}\text { Add cancer } \\
\text { characteristics }\end{array}$ & $0.91(0.81-1.02)$ & \\
\hline $\begin{array}{l}\text { Add management } \\
\text { characteristics }\end{array}$ & $0.96(0.85-1.07)$ & \\
\hline $\begin{array}{l}\text { Add provider } \\
\text { characteristics }\end{array}$ & $0.99(0.88-1.11)$ & \\
\hline \multirow[t]{2}{*}{ Adjust for clustering } & $0.99(0.90-1.08)$ & $0.89-1.11$ \\
\hline & OR $_{30-d \text { mortality }}(95 \% \mathrm{CI})$ & $\begin{array}{c}\text { Equivalence } \\
\text { interval }\end{array}$ \\
\hline \multicolumn{3}{|l|}{ VATS vs conventional } \\
\hline Unadjusted & $0.84(0.53-1.35)$ & \\
\hline $\begin{array}{l}\text { Add patient } \\
\text { characteristics }\end{array}$ & $0.77(0.48-1.24)$ & \\
\hline $\begin{array}{l}\text { Add cancer } \\
\text { characteristics }\end{array}$ & $0.81(0.50-1.31)$ & \\
\hline $\begin{array}{l}\text { Add management } \\
\text { characteristics }\end{array}$ & $0.82(0.51-1.31)$ & \\
\hline $\begin{array}{l}\text { Add provider } \\
\text { characteristics }\end{array}$ & $0.93(0.58-1.48)$ & \\
\hline Adjust for clustering & $0.93(0.57-1.50)$ & $0.72-1.28$ \\
\hline \multicolumn{3}{|c|}{$\begin{array}{l}\text { Patient characteristics are age, sex, race, and Charlson Comorbidity Index. Cancer } \\
\text { characteristics are histology, stage, and tumor size of greater than } 3 \mathrm{~cm} \text {. Management } \\
\text { characteristics are mediastinoscopy, mediastinal lymphadenectomy, and neoadjuvant } \\
\text { therapy. Provider characteristics are higher-volume surgeon, higher-volume hospital, } \\
\text { and teaching institution. Values are adjusted for clustering at the hospital level. The } \\
\text { hazard ratio }(H R) \text { of death is shown. The odds ratio }(O R) \text { approximates relative risk } \\
\text { when the outcome is rare. VATS, video-assisted thoracoscopy; } C I \text {, Confidence interval. }\end{array}$} \\
\hline
\end{tabular}

would suggest that the quality of a VATS procedure is unnecessarily variable, perhaps by provider. This possibility could not be further explored because there were too few events among the relatively few patients who underwent VATS by a low-volume surgeon or at a low-volume hospital.

VATS and conventional resection were equivalent in terms of long-term survival, but 2 caveats are worthy of mention. A key concern regarding the use of VATS is that enthusiasm over minimally invasive surgery and its purported benefits might come at the expense of oncologic principles of pulmonary resection: dissecting and ligating individual bronchovascular structures, obtaining negative margins, and performing adequate intraoperative staging of mediastinal lymph nodes. Although it has been demonstrated that an oncologic resection is possible with VATS, ${ }^{9,14,22,27}$ there remains concern that not all surgeons who perform VATS adhere to these principles. Although this dataset did not provide an opportunity to evaluate the appropriateness of a VATS operation, it did allow for indirect examination of clinically important departures from
TABLE 4. Stratified regression analysis evaluating provider influence on VATS outcomes

\begin{tabular}{lcc}
\hline & $\begin{array}{c}\text { Lower-volume } \\
\text { surgeon }\end{array}$ & $\begin{array}{c}\text { Higher-volume } \\
\text { surgeon }\end{array}$ \\
\hline $\begin{array}{l}\text { VATS vs conventional } \\
\text { Adjusted HR* } \\
(95 \% \mathrm{CI})\end{array}$ & $1.42(0.94-2.17)$ & $0.96(0.87-1.06)$ \\
& $\begin{array}{c}\text { Lower-volume } \\
\text { hospital }\end{array}$ & $\begin{array}{c}\text { Higher-volume } \\
\text { hospital }\end{array}$ \\
$\begin{array}{l}\text { VATS vs conventional } \\
\text { Adjusted HR* } \\
(95 \% \text { CI })\end{array}$ & $0.97(0.88-1.07)$ \\
& $\begin{array}{c}\text { Nonteaching } \\
\text { hospital }\end{array}$ & $\begin{array}{c}\text { Teaching } \\
\text { hospital }\end{array}$ \\
$\begin{array}{l}\text { VATS vs conventional } \\
\text { Adjusted HR* } \\
(95 \% \text { CI })\end{array}$ & $1.13(0.88-1.45)$ & $0.96(0.87-1.06)$ \\
\hline $\begin{array}{l}\text { VATS, Video-assisted thoracoscopy; } H R \text {, hazard ratio; } C I, \text { confidence interval. } \\
* \text { Adjusted for patient, cancer, management, and provider characteristics and cluster- } \\
\text { ing. Equivalence interval }=0.89 \text { to } 1.11 .\end{array}$
\end{tabular}

standard oncologic principles measured in terms of patient survival. Even though the overall analysis supported the equivalence of a VATS approach, stratified analyses suggested higher risks of death associated with VATS when performed by low-volume surgeons. Although volume might have been a requisite for achieving equivalent outcomes with VATS, a more likely explanation is that it was a surrogate for appropriately performed VATS resections. The findings from this study are consistent with the notion that VATS was at least as good as conventional resection but only to the extent that VATS was performed according to appropriate oncologic principles. A second caveat is that this study was not a randomized noninferiority trial and is therefore subject to the usual limitations of an observational study, including unmeasured confounding (patient selection factors known or suspected to affect outcomes and possibly result in bias).

Findings from this investigation are consistent with prior descriptions of an association between VATS and shorter $\operatorname{LOS}^{1,3}$ but challenge the notion that shorter LOS results in cost savings. Shorter LOS is plausibly explained by less pain, earlier ambulation, and fewer complications after a VATS resection, ${ }^{1,6,16}$ and if true, these benefits would reasonably be expected to translate into cost savings. One explanation for why there were no observed cost savings associated with VATS is that Medicare expenditures were likely related to an episode of care (ie, hospitalization for lung cancer resection) rather than specific attributes of that care, such as type of operation performed, LOS, or frequency of adverse events. Had expenditures for subsequent care (beyond the index hospitalization) been evaluated and adverse event rates truly been lower for VATS, then cost savings might have been observed. Also, although it appears that shorter 
LOS might not have resulted in cost savings for Medicare, it is likely that hospitals profited from patients who spent less time in the hospital. VATS might have been associated with shorter LOS because surgeons who commonly perform VATS might also frequently use clinical pathways and algorithms expediting postoperative care. ${ }^{28}$ It would be important to know how much of the association between VATS and shorter LOS is explained by the use of such pathways because these algorithms might also be applicable to patients who undergo open resection. Unfortunately, the limitations of the dataset precluded a more detailed health economic analysis.

This study had a number of limitations. Because Medicare claims were created for administrative rather than research purposes, we were unable to measure important clinical variables, such as lung function, performance status, and severity of underlying comorbidities. This might have resulted in inadequate risk adjustment and possibly biased our noninferiority-based analyses. Although clinical databases, such as the one maintained by the Society of Thoracic Surgeons, likely allow for better risk adjustment, the SEER-Medicare database more likely provides a nationally representative description of patterns of care and associated outcomes, at least at this time. Yet even the SEER-Medicare database might be somewhat limited in its generalizability if patterns of care and outcomes are different for patients 65 years and younger or those enrolled in health maintenance organizations or other health plans. However, because the median age of lung cancer is 70 years $^{29}$ and Medicare provides health care coverage for $97 \%$ of elderly Americans, SEER-Medicare data might very well be generalizable. Finally, missing data varied by approach to resection $(17 \%$ for standard resection and $13 \%$ for VATS) and might have biased our results. Because patients with missing covariate data had lower survival rates $(40 \%$ vs $45 \%, P<.001)$ and were excluded from the analysis, outcomes associated with the standard resection group might have been too optimistic in the case-complete analysis. Any such bias might have resulted in VATS appearing equivalent to conventional resection when in truth VATS might have been associated with better outcomes.

The findings from this study have several implications for clinical practice, surgical education, policy, and future research. In counseling patients on the risks and benefits of pulmonary resection, results from this study can be cited as additional evidence, limitations notwithstanding, supporting the equivalency of VATS and standard resection in terms of effectiveness. Because there might be variability in VATS outcomes across surgeons and hospitals, greater efforts should be taken to mandate standardized VATS training within cardiothoracic training programs. Additionally, hospitals and organizations might choose to require credentialing of surgeons in the appropriate use of VATS. Given the limitations of this and other studies, future investigations would ideally confirm the equivalence of VATS and standard resection in a randomized noninferiority trial. The feasibility of such a trial has been questioned on the basis of sample size and lack of clinical equipoise among individual surgeons. ${ }^{27}$ Demonstrating noninferiority in terms of safety will not likely be feasible because it would require 13,888 patients to demonstrate a $1 \%$ difference in 30-day mortality rates. In contrast, 2982 patients would be needed to demonstrate a $5 \%$ difference in overall survival rates. Given the high incidence of lung cancer, a multicenter approach might be a realistic option if equipoise were to exist. The feasibility of conducting multicenter noninferiority trials in surgical oncology has been demonstrated previously in the setting of operable colon cancer. ${ }^{30}$ In the interim, prospective observational studies should aim to re-evaluate the noninferiority of VATS by using clinical data for risk adjustment and quantify its purported benefits by using validated metrics for quality of life and functional status.

This study used the linked SEER-Medicare database. The interpretation and reporting of these data are the sole responsibility of the authors. The authors acknowledge the efforts of the Applied Research Program, National Cancer Institute; the Office of Research, Development and Information, Centers for Medicare and Medicaid Services; Information Management Services, Inc; and the SEER Program tumor registries in the creation of the SEER-Medicare database. The content is solely the responsibility of the authors and does not necessarily represent the official views of the National Cancer Institute or the National Institutes of Health. The authors are also grateful for additional resources made available through the University of Washington's Department of Surgery and the Surgical Outcomes Research Center, and the generosity of the Schilling Family.

\section{References}

1. Cattaneo SM, Park BJ, Wilton AS, Seshan VE, Bains MS, Downey RJ, et al. Use of video-assisted thoracic surgery for lobectomy in the elderly results in fewer complications. Ann Thorac Surg. 2008;85:231-6.

2. Daniels LJ, Balderson SS, Onaitis MW, D'Amico TA. Thoracoscopic lobectomy: a safe and effective strategy for patients with stage I lung cancer. Ann Thorac Surg. 2002;74:860-4.

3. Demmy TL, Curtis JJ. Minimally invasive lobectomy directed toward frail and high-risk patients: a case-control study. Ann Thorac Surg. 1999;68:194-200.

4. Hazelrigg SR, Nunchuck SK, LoCicero J 3rd. Video Assisted Thoracic Surgery Study Group data. Ann Thorac Surg. 1993;56:1039-43.

5. Jaklitsch MT, Pappas-Estocin A, Bueno R. Thoracoscopic surgery in elderly lung cancer patients. Crit Rev Oncol Hematol. 2004;49:165-71.

6. Kirby TJ, Rice TW. Thoracoscopic lobectomy. Ann Thorac Surg. 1993;56:784-6.

7. Landreneau RJ, Mack MJ, Hazelrigg SR, Naunheim K, Dowling RD, Ritter P, et al. Prevalence of chronic pain after pulmonary resection by thoracotomy or video-assisted thoracic surgery. J Thorac Cardiovasc Surg. 1994;107:1079-86.

8. Lewis RJ, Caccavale RJ, Sisler GE, Mackenzie JW. Video-assisted thoracic surgical resection of malignant lung tumors. J Thorac Cardiovasc Surg. 1992;104: 1679-87.

9. McKenna RJ Jr, Houck W, Fuller CB. Video-assisted thoracic surgery lobectomy: experience with 1,100 cases. Ann Thorac Surg. 2006;81:421-6.

10. Onaitis MW, Petersen RP, Balderson SS, Toloza E, Burfeind WR, Harpole DH Jr, et al. Thoracoscopic lobectomy is a safe and versatile procedure: experience with 500 consecutive patients. Ann Surg. 2006;244:420-5.

11. Petersen RP, Pham D, Burfeind WR, Hanish SI, Toloza EM, Harpole DH Jr, et al. Thoracoscopic lobectomy facilitates the delivery of chemotherapy after resection for lung cancer. Ann Thorac Surg. 2007;83(4):1245-50. 
12. Shigemura N, Akashi A, Funaki S, Nakagiri T, Inoue M, Sawabata N, et al. Longterm outcomes after a variety of video-assisted thoracoscopic lobectomy approaches for clinical stage IA lung cancer: a multi-institutional study. $J$ Thorac Cardiovasc Surg. 2006;132:507-12.

13. Sugiura H, Morikawa T, Kaji M, Sasamura Y, Kondo S, Katoh H. Long-term benefits for the quality of life after video-assisted thoracoscopic lobectomy in patients with lung cancer. Surg Laparosc Endosc Percutan Tech. 1999;9:403-8.

14. Swanson SJ, Herndon JE 2nd, D'Amico TA, Demmy TL, McKenna RJ Jr, Green MR, et al. Video-assisted thoracic surgery lobectomy: report of CALGB 39802-a prospective, multi-institution feasibility study. J Clin Oncol. 2007; 25:4993-7.

15. Walker WS, Codispoti M, Soon SY, Stamenkovic S, Carnochan F, Pugh G. Longterm outcomes following VATS lobectomy for non-small cell bronchogenic carcinoma. Eur J Cardiothorac Surg. 2003;23:397-402.

16. Whitson BA, Andrade RS, Boettcher A, Bardales R, Kratzke RA, Dahlberg PS, et al. Video-assisted thoracoscopic surgery is more favorable than thoracotomy for resection of clinical stage I non-small cell lung cancer. Ann Thorac Surg. 2007;83:1965-70.

17. Kaul S, Diamond GA. Good enough: a primer on the analysis and interpretation of noninferiority trials. Ann Intern Med. 2006;145:62-9.

18. Warren JL, Klabunde CN, Schrag D, Bach PB, Riley GF. Overview of the SEERMedicare data: content, research applications, and generalizability to the United States elderly population. Med Care. 2002;40(suppl):IV3-18.

19. Farjah F, Wood D, Yanez N, RG S, Krisnadasan B, Flum D. Temporal trends in the management of potentially resectable lung cancer. Ann Thorac Surg. 2008;85:1850-5.

20. Klabunde CN, Potosky AL, Legler JM, Warren JL. Development of a comorbidity index using physician claims data. J Clin Epidemiol. 2000;53:1258-67.
21. Hollenbeck BK, Hong J, Zaojun Y, Birkmeyer JD. Misclassification of hospital volume with surveillance, epidemiology, and end results Medicare data. Surg Innov. 2007;14:192-8.

22. Jackson TD, Kaplan GG, Arena G, Page JH, Rogers SO Jr. Laparoscopic versus open resection for colorectal cancer: a metaanalysis of oncologic outcomes. J Am Coll Surg. 2007;204:439-46.

23. Finlayson SR, Laycock WS, Birkmeyer JD. National trends in utilization and outcomes of antireflux surgery. Surg Endosc. 2003; 17:864-7.

24. Rutledge R, Fakhry SM, Baker CC, Meyer AA. The impact of laparoscopic cholecystectomy on the management and outcome of biliary tract disease in North Carolina: a statewide, population-based, time-series analysis. J Am Coll Surg. 1996;183:31-45.

25. Samuel I, Mason EE, Renquist KE, Huang YH, Zimmerman MB, Jamal M. Bariatric surgery trends: an 18-year report from the International Bariatric Surgery Registry. Am J Surg. 2006; 192:657-62.

26. Dimick JB, Welch HG, Birkmeyer JD. Surgical mortality as an indicator of hospital quality: the problem with small sample size. JAMA. 2004;292:847-51.

27. D'Amico TA. Thoracoscopic lobectomy: evolving and improving. J Thorac Cardiovasc Surg. 2006;132:464-5.

28. McKenna RJ Jr, Mahtabifard A, Pickens A, Kusuanco D, Fuller CB. Fast-tracking after video-assisted thoracoscopic surgery lobectomy, segmentectomy, and pneumonectomy. Ann Thorac Surg. 2007;84:1663-8.

29. Little AG, Gay EG, Gaspar LE, Stewart AK. National survey of non-small cell lung cancer in the United States: epidemiology, pathology and patterns of care. Lung Cancer. 2007;57:253-60.

30. Clinical Outcomes of Surgical Therapy Study Group. A comparison of laparoscopically assisted and open colectomy for colon cancer. $N$ Engl J Med. 2004; 350:2050-9.

APPENDIX 1. Billing codes used to define staging and therapy

\begin{tabular}{|c|c|c|c|c|c|c|c|c|c|c|c|}
\hline \multicolumn{12}{|l|}{ Resection } \\
\hline HCPCS & 32480 & 32484 & 32663 & & & & & & & & \\
\hline \multicolumn{12}{|c|}{ Chemotherapy } \\
\hline \multirow[t]{7}{*}{ HCPCS } & 95549 & 96400 & 96404 & 96406 & 96410 & 96412 & 96414 & 96420 & 96420 & 96422 & 96423 \\
\hline & 96425 & 96440 & 96445 & 96450 & 96542 & 96545 & C9017 & J0182 & $\mathrm{J} 8510$ & J8530 & $\mathrm{J} 8560$ \\
\hline & $\mathrm{J} 8610$ & J899 & J9000 & J9001 & J9010 & J9045 & J9060 & J9062 & J9070 & J9080 & J9090 \\
\hline & J9091 & J9092 & J9093 & J9094 & J9095 & J9096 & J9097 & J9170 & J9180 & J9181 & J9182 \\
\hline & J9190 & J9201 & J9206 & J9208 & J9230 & J9250 & J9260 & J9265 & J9280 & J9290 & J9291 \\
\hline & J9350 & J9360 & J9370 & J9375 & J9380 & J9390 & J9999 & Q0083 & Q0084 & Q0085 & Q0125 \\
\hline & Q0127 & Q0128 & Q0129 & S0178 & S0182 & S9329 & S9330 & S9331 & & & \\
\hline ICD-9 & V58.1 & V66.2 & V67.2 & \multicolumn{2}{|l|}{99.25} & & & & & & \\
\hline $\mathrm{RCC}$ & 0331 & 0332 & 0335 & & & & & & & & \\
\hline \multicolumn{12}{|c|}{ Radiation therapy } \\
\hline \multirow[t]{8}{*}{ HCPCS } & 31643 & 77300 & 77301 & 77305 & 77310 & 77315 & 77321 & 77326 & 77327 & 77328 & 77331 \\
\hline & 77332 & 77333 & 77334 & 77336 & 77370 & 77380 & 77381 & 77399 & 77401 & 77402 & 77403 \\
\hline & 77404 & 77406 & 77407 & 77408 & 77409 & 77411 & 77412 & 77413 & 77414 & 77416 & 77417 \\
\hline & 77418 & 77419 & 77420 & 77425 & 77427 & 77430 & 77431 & 77432 & 77470 & 77499 & 77520 \\
\hline & 77522 & 77523 & 77525 & 77750 & 77761 & 77762 & 77763 & 77781 & 77782 & 77783 & 77784 \\
\hline & 77799 & $\mathrm{C} 1716$ & $\mathrm{C} 1717$ & $\mathrm{C} 1718$ & C1719 & $\mathrm{C} 1720$ & $\mathrm{C} 1790$ & C1791 & $\mathrm{C} 1792$ & C1793 & C1794 \\
\hline & C1795 & C1796 & C1797 & C1798 & C1799 & C1800 & C1801 & C1802 & $\mathrm{C} 1803$ & C1804 & C1805 \\
\hline & C1806 & $\mathrm{C} 2616$ & G0126 & G0173 & & & & & & & \\
\hline \multirow[t]{2}{*}{ ICD-9 } & V58.0 & V66.1 & V67.1 & 92.20 & 92.21 & 92.22 & 92.23 & 92.24 & 92.26 & 92.27 & 9.28 \\
\hline & 92.29 & 92.30 & 92.31 & 92.32 & 92.33 & 92.39 & & & & & \\
\hline \multicolumn{12}{|l|}{ PET } \\
\hline HCPCS & G0125 & G0126 & G0210 & G0211 & G212 & G0234 & 78810 & & & & \\
\hline \multicolumn{12}{|c|}{ Mediastinoscopy } \\
\hline HCPCS & 39400 & & & & & & & & & & \\
\hline \multicolumn{12}{|c|}{ Mediastinal lymphadenectomy } \\
\hline HCPCS & 38746 & & & & & & & & & & \\
\hline
\end{tabular}

